\title{
O gênero debate no ensino de português: uma investigação sobre usos do liuro didático em sala de aula
}

The genre debate in Portuguese language lessons: an investigation about uses of textbooks

Bruno Alves Pereira Universidade Estadual da Paraíba - UEPB Williany Miranda da Silva Universidade Federal de Campina Grande - UFCG DOI: https://doi.org/10.5902/2176148538822

Resumo: O estudo apresentado neste artigo buscou responder ao seguinte questionamento: há um efeito de solidarização ou de sobreposição entre os projetos didáticos de duas professoras para a abordagem do gênero debate em sala de aula e o projeto didático do livro utilizado por essas profissionais? Inserido na perspectiva da Linguística Aplicada e de caráter descritivo-interpretativo, o estudo em questão está fundamentado nos conceitos de solidarização e sobreposição como efeitos da transposição didática (BRONCKART; GIGER, 1998; RAFAEL, 2001a, 2001b) e de projeto didático (BUNZEN, 2009, 2014; MATENCIO, 2001; ROJO, 2006).

Palavras-chave: Debate. Livro didático. Aula de português. Solidarização. Sobreposição.

Abstract: This study aims at answering the following question: is there a solidarization effect or a superposition effect between the two teachers' didactic projects to teach the genre debate and the textbook's didactic project used by those teachers? This is a descriptive-interpretative investigation in Applied Linguistics and is based on the studies about solidarization and superposition as effects of the didactic transposition (BRONCKART; GIGER, 1998; RAFAEL, 2001a, 2001b) and on the studies about didactic project (BUNZEN, 2009, 2014; MATENCIO, 2001; ROJO, 2006).

Keywords: Debate. Textbook. Portuguese language lessons. Solidarization. Superposition. 


\section{Introdução}

Desde a década de 80 do século XX, o livro didático tem ocupado um lugar de destaque em investigações brasileiras da área de Letras e Linguística. Se, até o final dos anos 90, o foco principal dessas pesquisas era a análise de conteúdos e de metodologias desse material, nos últi-

Bruno Alves

Pereira

Williany

Miranda da

Silva

176 mos anos, temos presenciado o surgimento, principalmente no âmbito da Linguística Aplicada, de um enfoque nos processos de produção, escolha e uso do livro didático (cf. BATISTA; ROJO, 2005; BUNZEN, 2014). É nessa perspectiva mais recente de investigação que enquadramos o estudo $^{1}$ aqui apresentado cujo foco é a transposição didática/didatização do gênero oral formal debate realizada por um livro didático de Língua Portuguesa e por professores que utilizaram esse material em sala de aula.

Ao olhar para os usos do livro didático, especificamente, de um capítulo destinado ao trabalho com a oralidade, a pesquisa buscou responder ao seguinte questionamento: há um efeito de solidarização ou de sobreposição entre os projetos didáticos de duas professoras para abordagem do gênero debate em sala de aula e o projeto didático do livro utilizado por essas profissionais? Inserido na perspectiva da Linguística Aplicada e de caráter descritivo-interpretativo, o estudo foi guiado pelos seguintes objetivos: a) identificar a compreensão de debate e o modo e a perspectiva de tratamento da oralidade revelados pelas estratégias didático-discursivas que compõem o projeto didático da unidade "Os elementos do debate" do volume destinado ao nono ano do ensino fundamental do livro didático Projeto Araribá; b) identificar a compreensão de debate e o modo e a perspectiva de tratamento da oralidade revelados pelas estratégias didático-discursivas mobilizadas por duas professoras que utilizaram esse material em sala de aula; e c) verificar se há um efeito de solidarização ou de sobreposição entre o projeto do livro e os projetos das duas professoras.

De modo a alcançar esses objetivos e, consequentemente, responder à questão posta acima, organizamos este artigo em seis seções. Depois desta introdução, evidenciamos os fundamentos teóricos e, em

1 Os dados analisados na dissertação de mestrado $O$ debate no ensino de português: do livro didático à sala de aula, defendida em 2011 no Programa de Pós-Graduação em Linguagem e Ensino (PPGLE) da Universidade Federal de Campina Grande (UFCG), recebem aqui um novo viés explicativo no âmbito do projeto de pesquisa "Configurações de ensino em práticas multidisciplinares de linguagem" (CAAE: 94344318.6.0000.5182). 
seguida, descrevemos o corpus do estudo. A análise está dividida em duas seções: "O projeto didático da unidade 'Os elementos do debate" e “Solidarização ou sobreposição de projetos didáticos?". Posteriormente, apresentamos nossas considerações finais.

\section{Fundamentos teóricos}

Esta seção está subdividida em quatro momentos. Inicialmente, caracterizamos o debate a partir de estudos da Comunicação e da Linguística. Em seguida, apresentamos os modos e as perspectivas de tratamento da oralidade no ensino propostos por Barros-Mendes (2005). Na sequência, evidenciamos o conceito de projeto didático com o qual operamos. Por fim, com base em Rafael (2001a, 2001b), propomos a utilização dos conceitos de solidarização e de sobreposição para explicar os usos que

O gênero debate no ensino de português

\subsection{0 que é um debate?}

Com base em estudos da Comunicação (BARBOSA FILHO, 2009; SOUZA, 2004) e da Linguística, principalmente, da Análise da Conversação e da Linguística de Texto (GARCIA, 1980; MARCUSCHI, 2001; KERBRAT-ORECCHIONI, 1990), temos compreendido o debate como a interação que reúne, pelo menos, três pessoas, principalmente, nos contextos jornalístico e escolar/acadêmico, para tratar de um assunto que permita uma divergência de opiniões, como, por exemplo, em "o rodeio maltrata os animais?" (sim ou não) ou ainda "redução da maioridade penal" (contra ou a favor) ${ }^{2}$.

A partir dos estudos mencionados, temos proposto a seguinte representação das relações entre o debate e outros três gêneros orais - a conversa, a discussão e a entrevista.

2 "O rodeio maltrata os animais?" foi a questão norteadora de um debate exibido em 2010 pelo programa "MTV Debate", do canal televisivo MTV Brasil, e "Redução da maioridade penal” foi o tema do programa "Debate" do canal Futura em 2017. 
Bruno Alves

Pereira

Williany

Miranda da

Silva

178

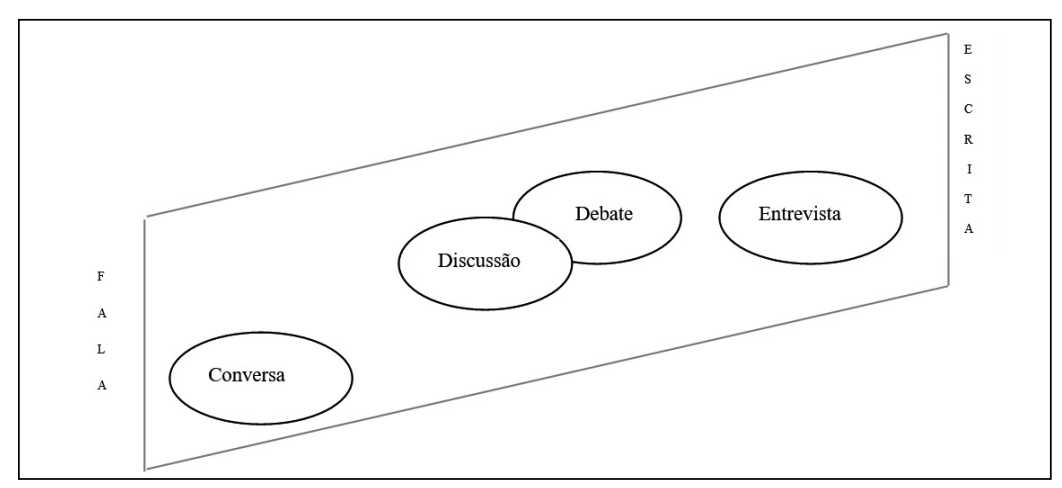

Figura 1: Contínuo de relações entre alguns gêneros orais; Fonte: elaborado a partir de Marcuschi (2001, p. 41)

Dos quatro gêneros representados no contínuo fala-escrita na Figura 1, o debate e a entrevista são os que apresentam características mais ritualizadas: ocorrem com tema, local, tempo, participantes e público definidos anteriormente à interação. Esses aspectos contribuem para caracterizá-los como gêneros mais formais que a conversa, por exemplo. Porém, um aspecto auxilia a diferenciação entre eles: enquanto, no debate, o confronto de opiniões é característica fundamental; na entrevista, ele é facultativo.

A presença de um tema controverso aproxima o debate da discussão. Por esse motivo, esses dois gêneros estão interseccionados na Figura 1. Dois aspectos contribuem para a diferenciação entre o debate e a discussão. Primeiro, a presença de uma questão norteadora que implique o surgimento de duas opiniões (sim ou não; contra ou a favor) não necessariamente se encontra em uma discussão (DE PIETRO; KANEMAN-POUGATH; ÉRARD, 1996/1997). O estabelecimento de um tema controverso, como "o suicídio", por exemplo, e não de uma pergunta geral norteadora da interação, provavelmente resultará na produção de uma discussão, e não de um debate, pois, a priori, haveria apenas um lado a ser defendido: "o suicídio deve ser prevenido". Na atualidade, em grande parte do mundo, não se espera que alguém defenda que não há necessidade de prevenção ao suicídio. Segundo, a diferenciação entre o debate e a discussão, como já mencionado anteriormente, advém do caráter menos ritualizado da última interação mencionada, na qual, por exemplo, a figura do moderador, responsável pela gestão da palavra, pode não existir.

Apresentada a compreensão de debate com a qual operamos, na subseção seguinte, evidenciamos dois modos de tratamento da oralidade no ensino. 


\subsection{Modos e perspectivas de tratamento da linguagem oral no ensino}

Ao investigar livros didáticos de Língua Portuguesa para os anos finais do ensino fundamental, Barros-Mendes (2005) identificou dois modos de tratamento da linguagem oral: como meio e como objeto de ensino.

No primeiro modo mencionado, a linguagem oral não é um objeto autônomo, mas o meio que permite a abordagem de outros objetos do ensino de Língua Portuguesa, quais sejam: a leitura e a compreensão, a produção de textos escritos e a exploração de aspectos gramaticais. Já o segundo modo enfatiza o ensino sistemático de gêneros textuais/ discursivos orais, o que pode ser feito a partir de três perspectivas. $\mathrm{Na}$ primeira delas, a da imersão, o professor requisita a produção de um dado gênero sem desenvolver previamente um ensino sistemático dele,

o gênero

debate no ensino de português pois acredita que a produção desse texto implicará, quase que automaticamente, no domínio do gênero pelo discente. Na perspectiva da transmissão, inicialmente, o professor apresenta as características de um dado gênero e, posteriormente, solicita a produção de um exemplar dele. Nesse caminho, defende-se que a apresentação de uma definição do gênero é condição suficiente para que os alunos possam produzi-lo. Por fim, a terceira perspectiva que toma a linguagem como objeto de ensino, a da reflexão, propõe que o domínio de um dado gênero é feito através de um processo que envolve a observação de bons exemplares dele disponíveis em nossa sociedade e sucessivas produções desse texto que sejam guiadas por avaliações com critérios bem definidos.

\subsection{0 que é um projeto didático?}

Seguindo estudos desenvolvidos na perspectiva da Linguística Aplicada (BUNZEN, 2009, 2014; MATENCIO, 2001; ROJO, 2006), temos defendido que tanto o professor em sala de aula quanto o(s) autor(es) de um material a ser utilizado nesse espaço possuem um projeto didático.

O conceito de projeto didático do professor foi pensado, originalmente, no âmbito da tese de doutoramento Estudo da língua falada e aula de língua materna: uma abordagem processual da interação professor/alunos, na qual Matencio (2001) examinou aulas de português e de francês como línguas maternas buscando propor um modelo de explicação da interação que ocorre nesse evento comunicativo. Matencio defende que o professor é o responsável pelo gerenciamento do evento aula e, por esse motivo, esse profissional possui um plano 
Bruno Alves

Pereira

Williany

Miranda da

Silva

180

interativo preliminar à interação que pode ser entendido como "as estratégias didático-discursivas a serem utilizadas para obtenção da finalidade global do encontro" (MATENCIO, 2001, p. 87). Tendo em vista que a autora não define precisamente estratégia didático-discursiva na tese, temos compreendido essa noção como "o que o professor faz ou requisita discursivamente para atingir a finalidade global de uma aula ou de uma sequência de aulas" (PEREIRA, 2011, p. 18).

De modo a tornar a noção de estratégia didático-discursiva mais compreensível, pensemos em dois exemplos. Numa aula, cuja finalidade seja a compreensão das funções dos participantes de um debate, uma possível estratégia mobilizada pelo professor pode ser a observação de um debate televisivo ou da transcrição dele. Já numa sequência de aulas cuja finalidade seja o estudo do gênero debate, a elaboração de uma listagem de argumentos sobre um tema polêmico pode ser uma considerada uma estratégia didático-discursiva.

Para Rojo (2006, p. 99), o projeto didático do autor de um material de ensino inclui, entre outros aspectos, uma compreensão sobre "o que ensinar", ou seja, a escolha de determinados objetos de ensino ou ainda de aspectos dele, e uma sobre "como ensinar", que, em nosso entendimento, são as estratégias didático-discursivas.

\subsection{Solidarização e sobreposição: efeitos da transposição didática} No início deste século, Rafael (2001a, 2001b) estudou a atualização dos conceitos de "texto" e "coesão textual" em aulas de estagiários em um curso de Letras - Língua Portuguesa de uma universidade pública do Nordeste brasileiro e de professores egressos desse mesmo curso. A partir das contribuições de Chevallard (1991) e de Bronckart e Giger (1998), que compreendem a transposição didática, em linhas gerais, como a transformação de um objeto científico em objeto de ensino, Rafael apontou a existência de dois efeitos dessa transposição: a solidarização e a sobreposição.

O primeiro desses efeitos ocorreria quando o docente faz "uso de termo e/ou de noções teóricas vindos de pelo menos duas fontes diferentes de conhecimentos de referência para analisar um fato linguístico" (RAFAEL, 2001b, p. 165), sem que haja uma contradição teórica, o que possivelmente resultará em uma ampliação do termo ou da noção. A solidarização acontece, por exemplo, conforme Rafael aponta em seu tese, quando uma professora egressa do curso em estudo, em uma dada 
aula de resolução de questões sobre ambiguidade, utiliza conceitos da Gramática Tradicional (tipo de oração, pronome e oração adjetiva) para construir junto com os alunos a noção de anáfora, advinda da Linguística Textual.

Já a sobreposição ocorreria quando a tentativa de fazer equivaler termos ou noções teóricas vindas de fontes distintas resultasse em uma contradição teórica e, consequentemente, em uma redução. Rafael exemplifica a sobreposição a partir da análise da aula de um estagiário na qual o termo conjunção, proveniente da Gramática Tradicional, foi equiparado ao de operador argumentativo, advindo da Linguística Textual, o que, na visão desse autor, implica na redução do último termo mencionado.

Neste trabalho, utilizamos os conceitos de solidarização e de soO gênero debate no ensino de português

breposição para explicar aspectos da transposição didática/didatização do gênero debate realizada por duas professoras que utilizam o mesmo livro didático em sala de aula. Para atender a esse objetivo, fizemos uma releitura da proposta de Rafael. Conforme evidenciamos na análise apresentada adiante, defendemos que há solidarização entre os projetos do livro e do professor quando eles apontam para um mesmo caminho de tratamento do objeto de ensino. Há sobreposição quando o projeto do professor aponta para um caminho teórico-metodológico de tratamento do objeto de ensino que é diferente do projeto do livro.

\section{0 corpus}

O corpus em análise neste trabalho é híbrido. A parte documental dele é formada pelas 43 (quarenta e três) páginas da unidade "Os elementos do debate", do volume destinado aos alunos do nono ano do ensino fundamental do livro didático Projeto Araribá, da editora Moderna, aprovado pelo Programa Nacional do Livro Didático (PNLD) para o triênio 20082010. Participaram na elaboração desse livro, que tem a organização assinada pela própria editora Moderna, cinco profissionais: Áurea Regina Kanashiro, Daniela Cristina Pinheiro Cohen, Maria Tereza Rangel Arruda Campos, Rosana Correa Pereira El Kadri e Rosane Limoli Paim Pamplona.

A outra parte do corpus, proveniente de observação de campo realizada em 2009, é composta por 29 (vinte e nove) aulas de duas professoras, aqui identificadas pelos pseudônimos Margarida e Violeta, que utilizavam o referido material em suas aulas que aconteciam no período 
Bruno Alves

Pereira

Williany

Miranda da

Silva

182

vespertino em duas escolas subordinadas à Secretaria de Educação do estado da Paraíba. As professoras colaboradoras da investigação tinham perfis bem distintos: Margarida, que, à época, tinha 44 (quarenta e quatro) anos de idade e atuava como docente há mais de duas décadas, ensinava Língua Portuguesa nos anos finais do ensino fundamental, mesmo sem ser formada para tal função, há mais de dez anos. Licenciada em Pedagogia, Margarida trabalhava nos anos iniciais e finais do ensino fundamental e no ensino médio na modalidade Educação de Jovens e Adultos (EJA). Violeta, por sua vez, possuía graduação e mestrado na área de Letras, mas contava com apenas um ano de tempo de docência. Essa docente atuava nos anos finais do ensino fundamental, no ensino médio e, como substituta, no ensino superior público.

De posse de anotações de diário de campo e das transcrições das gravações em áudio de 20 (vinte) aulas de Margarida e 9 (nove) de Violeta, para a sistematização desses dados e, consequentemente, identificação das estratégias didático-discursivas, utilizamos o instrumento sinopse, que tem como objetivo permitir uma visualização geral de uma sequência de aulas e, consequentemente, facilitar a análise a ser feita desse material proveniente de observação e gravação (SCHNEUWLY; DOLZ, 2009). Seguindo caminho trilhado por Bunzen (2009), qual seja, a utilização do instrumento acima mencionado para observação de material didático impresso, elaboramos também uma sinopse da unidade "Os elementos do debate". Nas duas seções seguintes, apresentamos a análise do corpus aqui descrito.

\section{0 projeto didático da unidade "Os elementos do debate"}

A elaboração e a análise da sinopse da unidade "Os elementos do debate" permitiram a identificação de 11 (onze) estratégias didático-discursivas sugeridas pelos autores do livro didático Projeto Araribá para abordar o gênero debate nas salas de aula do nono ano. 6 (seis) estratégias, a exemplo de "produção de um debate", são sugeridas, pelo menos, mais de uma vez.

Conforme evidenciado no Quadro 1, a seguir, as estratégias identificadas podem ser agrupadas em dois grandes grupos hierarquicamente superiores, o que nos leva a postular a existência de macro e microestratégias. À macroestratégia "leitura e análise da transcrição de um debate", pertencem 6 (seis) microestratégias, como "observação da transcrição de um debate" e "observação de pontos de vistas e de ar- 
gumentos em um gênero escrito". Já à macroestratégia "produção de debates", estão relacionadas 5 (cinco) microestratégias.

\section{Quadro 1: Estratégias didático-discursivas sugeridas no livro didá- tico em análise.}

\begin{tabular}{|c|c|}
\hline $\begin{array}{l}\text { Leitura e análise da trans- } \\
\text { crição de um debate }\end{array}$ & $\begin{array}{l}\text { - Levantamento de hipóteses sobre a funcionalidade do } \\
\text { gênero debate e sobre uma temática polêmica; } \\
\text { - Observação da transcrição de um debate }{ }^{3} \text {; } \\
\text { - Análise da transcrição de um debate (Identificação das } \\
\text { principais ideias veiculadas no debate transcrito); } \\
\text { - Produção de uma discussão regrada em pequenos grupos; } \\
\text { - Análise da transcrição de um debate (identificação das } \\
\text { principais características do gênero debate); } \\
\text { - Observação de pontos de vistas e de argumentos em } \\
\text { um gênero escrito; } \\
\text { - Identificação dos recursos linguísticos de um debate. }\end{array}$ \\
\hline Produção de debates & $\begin{array}{l}\text { - Observação de pontos de vista e de argumentos em } \\
\text { gêneros escritos; } \\
\text { - Construção da situação comunicativa de um debate a } \\
\text { ser realizado em sala de aula (Debate 1); } \\
\text { - Produção de um debate (Debate 1); } \\
\text { - Avaliação do debate produzido (Debate 1); } \\
\text { - Construção do conteúdo temático de um debate a ser } \\
\text { realizado em sala de aula (Debate 2); } \\
\text { - Construção da situação comunicativa de um debate a } \\
\text { - ser realizado em sala de aula (Debate 2); } \\
\text { - Identificação do recursos linguísticos da argumentação; } \\
\text { - Produção de um debate (Debate 2); } \\
\text { - Avaliação do debate produzido (Debate 2); } \\
\text { - Construção do conteúdo temático de um debate a ser } \\
\text { realizado em sala de aula (Debate 3); } \\
\text { - Produção de um debate (Debate 3); } \\
\text { - Avaliação do debate produzido (Debate 3). }\end{array}$ \\
\hline
\end{tabular}

o gênero

debate no

ensino de

português

Fonte: sinopse elaborada pelos pesquisadores

No início da unidade "Os elementos do debate", é apresentada uma história em quadrinhos intitulada "Calvin e Haroldo", de autoria de Bill Watterson. As questões que acompanham o referido texto têm como objetivo fazer um levantamento de hipóteses sobre a funcionalidade de um debate. Em seguida, o livro apresenta a transcrição, intitulada "O uso da informática na educação", de um trecho do programa “Opinião Nacional” exibido pela TV Cultura.

3 Neste trabalho, diferenciamos "observação da transcrição de um debate" de "análise da transcrição de um debate". Em nossa compreensão, essa segunda estratégia implica a elaboração de respostas a perguntas que devem ser respondidas a partir da observação atenta da transcrição. 
Na seção "Estudo do texto", que aparece depois da transcrição, são sugeridas 4 (quatro) estratégias: "análise da transcrição de um debate"; "produção de uma discussão regrada em pequenos grupos"; "observação de pontos de vistas e de argumentos em um gênero escrito" e "identificação dos recursos linguísticos de um debate". Nessa

Bruno Alves

Pereira

Williany

Miranda da

Silva

184 seção, 3 (três) características principais do gênero foco da unidade são exploradas com mais ênfase: a presença da questão polêmica, os movimentos discursivos típicos da argumentação (opinião, argumentos, refutação, etc.) e os papéis dos integrantes de um debate (moderador e debatedores).

Depois de "leitura e análise da transcrição de um debate", tem início a macroestratégia "produção de debates", na qual o livro sugere a elaboração de três exemplares do gênero foco da unidade. Os debates 1 e 2 já apresentam as questões polêmicas norteadoras, quais sejam: "você é a favor ou contra a proibição da produção e do comércio de armas no Brasil?" e "é correto copiar trabalhos escolares disponíveis em sites da Internet?". Já no debate 3, a questão norteadora não aparece explícita e deve ser criada pelos discentes a partir da leitura de textos sobre a temática "a introdução de crianças com Síndrome de Down em salas de aula nas quais a maioria dos alunos não tem essa condição genética". Nesse segundo grande momento da unidade "Os elementos do debate", a produção de textos é pensada como um processo que envolve a criação de uma situação comunicativa, a construção do conteúdo temático através de diferentes modos e a avaliação dos exemplares produzidos.

A observação e a análise da sinopse da unidade "Os elementos do debate" e, consequentemente, das estratégias didático-discursivas que compõem o projeto didático do livro em questão permitem apontar que o debate é caracterizado como nos estudos da Comunicação e da Linguística aos quais fizemos referência anteriormente: um gênero formal argumentativo norteado por uma questão que permita a divergência de opiniões (sim ou não; contra ou a favor). Quanto ao modo e à perspectiva de tratamento da oralidade, é possível apontar que o debate é entendido como um objeto de ensino a ser abordado pelo caminho da reflexão, ou seja, em um processo que se inicia com a observação e a análise de exemplares do gênero e termina com a avaliação, baseada em critérios bem definidos, dos debates produzidos pelos discentes. 


\section{Solidarização ou sobreposição de projetos didáticos?}

Nesta seção, nosso intuito foi verificar se há um efeito de solidarização ou de sobreposição entre o projeto do livro didático, exposto anteriormente, e os projetos didáticos mobilizados em sala de aula pelas professoras colaboradoras deste estudo. Para tanto, inicialmente, elaboramos o Quadro 2 que contém as estratégias didático-discursivas utilizadas por Margarida e Violeta.

Quadro 2: Estratégias didático-discursivas mobilizadas pelas professoras colaboradoras do estudo.

\begin{tabular}{|c|c|}
\hline Margarida & Violeta \\
\hline $\begin{array}{l}\text { - Levantamento de hipóteses sobre as } \\
\text { características do gênero debate; } \\
\text { - Estudo de situações de debates represen- } \\
\text { tadas em dois textos impressos (Identifi- } \\
\text { cação das ideias principais veiculadas em } \\
\text { dois gêneros escritos / Estudo das princi- } \\
\text { pais características do gênero debate); } \\
\text { - Observação de pontos de vista e de argu- } \\
\text { mentos em gêneros escritos; } \\
\text { - Estudo das características gerais do } \\
\text { gênero debate; } \\
\text { - Observação da transcrição de um debate; } \\
\text { - Observação de pontos de vista e de argu- } \\
\text { mentos em gêneros escritos; } \\
\text { - Estudo das características gerais de um } \\
\text { debate; } \\
\text { - Construção da situação comunicativa de } \\
\text { um debate a ser realizado em sala de aula; } \\
\text { - Observação de pontos de vista e de argu- } \\
\text { mentos em gêneros escritos; } \\
\text { - Estudo das características gerais do } \\
\text { gênero debate; } \\
\text { - Construção do conteúdo temático de um } \\
\text { debate a ser realizado em sala de aula; } \\
\text { - Produção de um debate em sala de aula; } \\
\text { - Avaliação do debate produzido. }\end{array}$ & $\begin{array}{l}\text { - Construção da situação comunicativa de } \\
\text { um debate a ser realizado em sala de aula; } \\
\text { - Construção do conteúdo temático do } \\
\text { debate a ser realizado em sala de aula; } \\
\text { - Análise da transcrição de um debate; } \\
\text { - Construção do conteúdo temático do } \\
\text { debate a ser realizado em sala de aula; } \\
\text { - Análise da transcrição de um debate } \\
\text { (Identificação das ideias principais } \\
\text { veiculadas no debate transcrito / Estudo } \\
\text { das principais características do gênero } \\
\text { debate); } \\
\text { - Construção do conteúdo temático do } \\
\text { debate a ser realizado em sala de aula; } \\
\text { - Análise da transcrição de um debate } \\
\text { (Identificação das ideias principais } \\
\text { veiculadas no debate transcrito / Estudo } \\
\text { das principais características do gênero } \\
\text { debate; } \\
\text { - Produção de um debate; } \\
\text { - Avaliação do debate produzido. }\end{array}$ \\
\hline
\end{tabular}

o gênero

debate no ensino de português

Fonte: sinopses elaboradas pelos pesquisadores

Conforme indicado no quadro acima, a professora Margarida mobilizou 9 (nove) estratégias didático-discursivas. "Observação de pontos de vista e de argumentos em gêneros escritos" e "estudo das características gerais do gênero debate" foram utilizadas cada uma mais de uma vez. De modo semelhante ao livro didático, essa profissional inicia a sua sequência de aulas através do levantamento das hipóteses dos discentes 
acerca das características do gênero em questão. Para tanto, Margarida solicita a leitura da história em quadrinhos "Calvin e Haroldo" e a feitura da atividade que consta no exemplo 1 , a seguir.

\section{Exemplo 1}

Bruno Alves

Pereira

Williany

Miranda da

Silva

186

Livro p. 128

- Ler

- Depois da leitura, enfoque o que aconteceu.

- Quem são os personagens?

- Você já assistiu algum debate?

- De quem?

- $\mathrm{O}$ que achou?

No exemplo 1 está a solicitação feita por Margarida na primeira aula de abordagem do gênero debate: os alunos deveriam ler a história em quadrinhos que abre a unidade "Os elementos do debate" e elaborar respostas a cinco perguntas. As duas primeiras estavam diretamente relacionadas à leitura do texto multimodal em questão ("enfoque o que aconteceu" e "Quem são os personagens?"). A professora, possivelmente, esperava que os alunos identificassem que a história em quadrinhos apresenta os momentos na vida do garoto Calvin posteriores ao "debate" que acontecera entre esse personagem e o pai dele. As outras três perguntas presentes na solicitação de Margarida focalizavam as experiências discentes de observação de debates ("Você já assistiu algum debate?, "De quem?" e “O que achou?").

Depois de abordar a história em quadrinhos "Calvin e Haroldo", Margarida propõe a leitura da transcrição do debate "O uso da informática na sala de aula”, também presente no livro didático, e a elaboração de respostas, tanto oralmente quanto por escrito, a muitas das perguntas que visavam o estudo dessa transcrição. É importante enfatizar que, no entanto, pouco tempo é destinado por essa profissional à sistematização dos conhecimentos sobre o debate advindos da elaboração das respostas às perguntas solicitadas. Sendo assim, as características do debate enfatizadas pelo livro, como a presença da questão polêmica, os movimentos discursivos típicos da argumentação e os papéis do moderador e dos debatedores, são pouco evidenciadas no projeto didático da professora em questão. Em compensação, muitas vezes ao longo das aulas, Margarida ressalta que o debate é um gênero formal. 
Quando se afasta do livro didático, essa profissional propõe, através de atividades de autoria própria, a apreensão pelos alunos de definições acerca do gênero debate ("Explique com suas palavras o que é um debate" e "Palestra e debate tem algo a ver?" - perguntas presentes em atividades solicitadas pela docente), aproximando-se, assim, do modo de abordagem da linguagem oral como objeto de ensino na perspectiva da transmissão (BARROS-MENDES, 2005).

Os três debates sugeridos pelo livro na macroestratégia "produção de debates" não são feitos por Margarida em sala de aula. No entanto, ela realiza a leitura e a discussão das temáticas dos textos apresentados nessa macroestratégia que tinham, no projeto didático do livro, o objetivo de auxiliar os alunos na construção do conteúdo temático dos três debates

O gênero debate no ensino de português

Depois de mais de dez aulas nas quais a unidade "Os elementos do debate" vinha sendo abordada, em resposta a uma solicitação de Margarida, alguns discentes indicam "drogas" e "violência" como temas para um possível debate a ser feito em sala. A professora, então, propõe que, em grupos, os alunos elaborem cinco questões sobre esses temas, sem indicar explicitamente que essas perguntas seriam utilizadas em um debate.

De acordo com o Quadro 2, "produção de um debate em sala de aula" é a penúltima estratégia didático-discursiva do projeto de Margarida. Vejamos, no exemplo 2, trechos da aula na qual essa estratégia foi mobilizada.

\section{Exemplo $2^{4}$}

M pronto... então $\mathrm{F}$ e A na equipe dois... e S e $\mathrm{C}$ na equipe um... qual o assunto preferido violência ou droga... equipe um?

A1 drogas

M a equipe dois?

A4 drogas também /.../

P eu vou entregar a... C... e a de S a elas... e elas vão começando por aqui ((entrega aos alunos A1, A2, A3 e A4 as folhas com as perguntas elaboradas por eles anteriormente))

$\mathrm{M}$ então podem começar

4 As transcrições seguem as normas do projeto de Estudos da Norma Linguística Urbana Culta de São Paulo (NURC, 1998). 
eu vou fazer uma pergunta ao grupo é isso?... "o que as drogas eleva a fazer?"... a qualquer pessoa do seu grupo ((se dirige a A3)) o que as drogas nos leva a fazer? nos leva a fazer muitas loucuras que tipo?

Bruno Alves

Pereira

Williany

Miranda da

Silva assim... ficar calmo ( ) ansioso... às vezes... muito alto... assim muito leve

A4 a minha visão é que... drogas... leva a pessoas a fazer loucuras... como suicídio matar pessoas roubar... vender as coisas dentro de casa pra comprar droga... é isso

$\mathrm{M}$ pronto... agora você pode falar ((professora cede a palavra a A1))

No exemplo 2, que apresenta um trecho da décima oitava aula das vinte que compõem o projeto de Margarida, evidenciamos o momento no qual a docente inicia a produção do debate. Embora os alunos já tivessem indicado dois temas (drogas e violência), não havia sido estabelecido precisamente qual deles seria focalizado no exemplar de debate a ser feito em sala de aula. Os alunos que iriam assumir os papéis de debatedor e de moderador também não haviam sido determinados antes do início da aula apresentada acima. Depois de escolher os discentes que participariam como debatedores exatamente no início da décima oitava aula, Margarida, cujos turnos foram indicados pela letra $\mathrm{M}$ na transcrição, busca saber qual dos temas anteriormente elencados poderia ser o foco do debate a ser feito ("qual o assunto preferido violência ou drogas... grupo um?" e "a equipe dois?").

Sem saber exatamente como dar continuidade à interação, a professora busca saber do pesquisador (P), um dos autores deste artigo, o que poderia ser feito. Então, esse sugere que sejam entregues as folhas que continham as perguntas sobre as questões elaboradas anteriormente ("eu vou entregar a... C... e de S a elas... e elas vão começando por aqui"). Os debatedores recebem as folhas, mas continuam sem saber precisamente que papéis devem ser desempenhados por eles ("eu vou fazer uma pergunta ao grupo é isso?”). A interação, entendida por 
Margarida como um debate, continua, sem que tenha ficado claro que a docente seria a moderadora.

A análise do exemplo 2 permite dizer que a interação proposta se assemelha mais a uma discussão que a um debate. A definição do tema e dos papéis dos participantes não acontece com a antecedência que se espera em um debate. Além disso, não há o estabelecimento de uma pergunta polêmica que pudesse nortear a interação.

Em face da análise apresentada, é possível apontar que o debate não é tomado como um objeto de ensino. Com exceção do caráter formal, outras características desse gênero oral não são focalizadas no projeto didático mobilizado por Margarida. Quando aborda os diversos textos presentes na unidade "Os elementos do debate", a ênfase é dada à temática deles. Desse modo, a linguagem oral é, prioritariamente, tra-

O gênero debate no ensino de português tada por Margarida como um meio para leitura e discussão de textos escritos (BARROS-MENDES, 2005). Como mencionado anteriormente, por vezes, a linguagem oral é abordada por Margarida como objeto de ensino numa perspectiva transmissiva (BARROS-MENDES, 2005). Sendo assim, podemos dizer que há um efeito de sobreposição entre o projeto do livro didático e o projeto de Margarida, pois, enquanto a unidade "Os elementos do debate" compreende esse gênero de modo semelhante aos estudos da Comunicação e da Linguística, Margarida propõe a produção de interações que mais se parecem com discussões do que com debates. Além disso, o modo de tratamento da oralidade é distinto: para o livro didático, o debate é objeto de ensino a ser aprendido em uma perspectiva reflexiva; para Margarida, o "debate" é meio para leitura e discussão de textos escritos.

Passemos a observar o projeto didático da professora Violeta. De acordo com o Quadro 2, essa profissional mobilizou 5 (cinco) estratégias didático-discursivas. 2 (duas) delas - "construção do conteúdo temático do debate a ser realizado em sala de aula" e "análise da transcrição de um debate" - foram utilizadas mais de uma vez. Nesse processo, a presença do livro didático foi menor que no projeto de Margarida. Enquanto Violeta utilizou 2 (duas) das 8 (oito) seções da unidade "Os elementos do debate", Margarida fez uso de 7 (sete).

No exemplo 3, a seguir, evidenciamos um trecho da primeira aula de Violeta na qual a estratégia "construção da situação comunicativa de um debate em sala de aula" foi mobilizada. 


\section{Exemplo 3}

$\mathrm{V}$ agora eu pergunto pra vocês... alguém aqui... quando vai fazer a prova de matemática... o professor disse assim... pronto já entreguei a prova pode colocar a calculadora em cima da mesa?

Bruno Alves

Pereira

Williany

Miranda da

Silva

190

Als não

A1 assim era bom demais

/.../

V deixa eu dizer uma coisa pra vocês... se vocês são a favor de usar máquina calculadora... quais são os argumentos?... quais são as razões que vocês iam listar pra dizer não... eu acho que a gente poderia usar sim...a calculadora em sala de aula

A1 pra passar de ano mais fácil

V passar... mas isso seria forte pra dizer não... vamos fazer um acordo a gente vai usar a máquina porque a gente quer passar de ano mais fácil?

A1 ele ganha o dinheiro... o salário e a gente passa

A3 a gente pode até passar de ano mais fácil mas a gente não aprende ((alunos falam ao tempo))

/.../

V pra pensar o seguinte... qual situação aqui?... situação comunicativa... em que tem... pontos de vista diferentes... a gente vai estabelecer aqui... visões diferentes... opostas... em que um... cada um vai dizer assim... quais são seus argumentos?... o que que você utiliza para convencer o outro a dizer?... ah o uso da calculadora na sala de aula deve ser proibido... quais são seus argumentos pra fazer isso? /.../ nesse caso nós estamos diante de uma situação comunicativa e do gênero chamado debate... e pra esse gênero acontecer... o gênero debate... nós precisamos de alguns elementos que fazem parte disso /.../ então nesse caso aqui... precisa... pro debate aconteça... é preciso que haja um tema polêmico... como existiu agora... J deu a opinião dela disse já já se manifestou dizendo não pera aí... tem que levar isso em consideração também... então esse embate de opiniões diferentes que faz com que o debate aconteça... agora eu vou comunicar uma coisa pra vocês... nós faremos um debate... e um dos debatedores... um deles será o professor G ((cita o nome do professor de Matemática))... o professor G... de Matemática... ele vai ser um debatedor 
Na primeira aula de uma sequência de nove, Violeta (V) inicia a construção da situação comunicativa de um debate que foi realizado nas últimas aulas do projeto didático dessa docente. Inicialmente, Violeta instiga os alunos a refletirem sobre a presença da calculadora nas aulas de Matemática ("quando vai fazer a prova de matemática... o professor disse assim... pronto já entreguei a prova pode colocar a calculadora em cima da mesa?" e "se vocês são a favor de usar máquina calculadora... quais são os argumentos?"). Os alunos demonstram interesse pela temática e apresentam argumentos tanto favoráveis quanto contrários à utilização de calculadora nas aulas de Matemática ("pra passar de ano mais fácil" e "a gente pode até passar de ano mais fácil mas a gente não aprende"). Na sequência, Violeta evidencia algumas características do debate, como as presenças da divergência de opiniões

o gênero debate no ensino de português em virtude de uma questão polêmica e de movimentos argumentativos ("situação comunicativa... em que tem... pontos de vista diferentes" e “quais são seus argumentos pra fazer isso?"). Por fim, Violeta anuncia que a turma fará um debate no qual o professor de Matemática será um dos debatedores ("nós faremos um debate... e um dos debatedores... um deles será o professor G").

Construída a situação comunicativa do gênero a ser produzido em sala de aula, Violeta orienta os alunos a buscarem informações que possam ser utilizadas no debate. As aulas seguintes são destinadas à análise da transcrição apresentada pelo livro didático. Nesse processo, alguns exercícios são requisitados e, no processo de correção, Violeta enfatiza, como características do debate, a presença da questão polêmica, os papéis dos envolvidos nessa interação e a relação entre ponto de vista e argumentos. Na sétima e na oitava aulas, acontece o debate do qual participam Violeta, como moderadora, e dois alunos e o professor de Matemática, como debatedores. De modo semelhante ao projeto didático de Margarida, "avaliação do debate produzido" é a última estratégia didático-discursiva mobilizada. Porém, diferentemente da outra professora observada, Violeta propõe uma avaliação guiada por critérios bastante pontuais.

A compreensão de debate e o modo de tratamento da linguagem oral evidenciados no projeto de Violeta são muito semelhantes aos do projeto da unidade "Os elementos do debate". Sendo assim, há entre os projetos do livro didático Projeto Araribá e de Violeta uma solidarização. 


\section{Considerações finais}

Ao investigar a transposição didática/didatização de um gênero oral, o debate, em um livro didático e nas aulas das professoras Margarida e Violeta que fizeram uso desse material, acreditamos ter contribuído para ampliar o foco que tem sido dado, nas investigações, ao livro didá-

Bruno Alves

Pereira

Williany

Miranda da

Silva tico e à oralidade nesse material (BATISTA; ROJO, 2005; BUNZEN, 2014; MAGALHÃES, 2018).

Na unidade "Os elementos do debate" do livro Projeto Araribá, o debate é entendido de modo semelhante às propostas de caracterização dessa interação feitas pelos estudos da Comunicação e da Linguística: um gênero oral formal produzido por, no mínimo, três interactantes, dois debatedores e o moderador, que reunidos apresentam opiniões sustentadas por argumentos acerca de um tema que permite divergências (sim ou não; contra ou a favor). A análise das estratégias didático-discursivas permitiu verificar que esse material aborda a linguagem oral como um objeto de ensino numa perspectiva reflexiva.

$\mathrm{Na}$ análise dos projetos didáticos das duas professoras que utilizam o referido material, identificamos que a compreensão de debate de Violeta é muito semelhante à do livro didático; diferentemente de Margarida que, por vezes, não estabelece uma distinção entre o debate e a discussão, por exemplo. Verificamos também diferenças entres os modos de tratamento da linguagem oral revelados nos projetos didáticos das duas professoras: enquanto Violeta aborda o debate como objeto de ensino numa perspectiva reflexiva de modo semelhante ao livro didático, Margarida vê o debate, em alguns momentos, como meio para discussão de temáticas de textos e, em outros, como objeto de ensino numa perspectiva transmissiva.

Em face do exposto, podemos dizer que há um efeito de solidarização entre o projeto da unidade "Os elementos do debate" e o projeto de Violeta e um efeito de sobreposição entre o projeto do livro e o projeto de Margarida. Acreditamos que a explicação para a diferença de efeito entre os projetos do livro e das professoras possa ser encontrada na relação que Margarida e Violeta mantinham com os saberes produzidos na academia.

Margarida não possuía, à época da geração de dados, do ponto de vista legal, formação para atuação no ensino de Língua Portuguesa nos anos finais do ensino fundamental. Já Violeta, embora tivesse pouco tempo de experiência em sala de aula, era uma profissional que investia na 
formação. Em concordância com Magalhães (2001, p. 255), não estamos defendendo que "há uma relação direta entre saber a teoria e alcançar bons resultados na sua apresentação didática", no entanto, ainda compartilhando das ideias dessa autora (2001, p. 254), acreditamos que "quando o profissional compreende, teoricamente, o porquê trabalhar" determinado objeto de ensino, o que parece ser o caso de Violeta, "ele é capaz de construir o 'como' trabalhá-lo" de modo muito mais contundente do que aquele profissional que ainda não teve essa compreensão teórica.

O gênero debate no ensino de

\section{REFERÊNCIAS}

BARROS-MENDES, A. N. N. A linguagem oral nos livros didáticos de língua portuguesa do ensino fundamental $-3^{\circ}$ e $4^{\circ}$ ciclos: algumas reflexões. $211 \mathrm{f}$. Tese (Doutorado em Linguística Aplicada e Estudos da Linguagem). Faculdade de Filosofia, Comunicação, Letras e Artes, Pontifícia Universidade Católica de São Paulo. São Paulo, 2005.

BATISTA, A. A. G; ROXO, R. Livros escolares no Brasil: a produção científica. In: VAL, M. G. C; M. B (org.) Livros didáticos de língua portuguesa: letramento e cidadania. Belo Horizonte: Autêntica/ Ceale, 2005, p. 13-45.

BARBOSA FILHO, A. Gêneros radiofônicos: os formatos e os programas em áudio. 2. ed. São Paulo: Paulinas, 2009.

BRONCKART, J. P.; GIGER, I. P. La transposition didactique: histoire et perspectives. Pratiques. Metz, p. 35-58, 1998.

BUNZEN, C. Análise de livros didáticos de português no campo da linguística aplicada: possibilidades e desafios. In: GONÇALVES, A. V.; SILVA, W. R.; GÓIS, M. L. S. (org.) Visibilizar a linguística aplicada: abordagens teóricas e metodológicas. Campinas, SP: Pontes, 2014, p. 269-291.

Dinâmicas discursivas na aula de português: usos do livro didático e projetos didáticos autorais. 233f. Tese (Doutorado em Linguística Aplicada). Instituto de Estudos da Lingaguem, Universidade Estadual de Campinas. Campinas-SP, 2009. 
CHEVALLARD, Y. La transposition didactique: du savoir savant au savoir enseigné. 2. ed. Grenoble: La Pensee Sauvage, 1991.

DE PIETRO, J-F.; KANEMAN-POUGATH, M.; ÉRARD, S. Un modèle didactique du 'débat': De l'objet social à la pratique scolaire. Enjeux, Bruno Alves Genebra, n. 39-40, p. 100-129, 1996/1997.

Pereira

Williany

GARCIA, C. Argumenter à l'oral. De la discussion au débat. Pratiques, Miranda da

Silva Metz, n. 28, p. 95-124, 1980.

KERBRAT-ORECCHIONI, C. Les interactions verbales. Tomo I. Paris, Armand Colin, 1990.

MAGALHÃES, T. G. Oralidade e ensino de língua portuguesa no Brasil: uma leitura. In: __ _ CRISTOVÃO, V. (org.) Oralidade e ensino de Língua Portuguesa. Campinas, SP: Pontes, 2018, p. 15-38.

MAGALHÃES, L. M. Modelos de educação continuada: os diferentes sentidos da formação reflexiva do professor. In: KLEIMAN, A. (org.) Formação do professor: perspectivas da linguística aplicada. Campinas, SP: Mercado de Letras, 2001, p. 239-259.

MARCUSCHI, L. A. Da fala para a escrita: atividades de retextualização. São Paulo: Cortez, 2001.

MATENCIO, M. L. M. Estudo da língua falada e aula de língua materna: uma abordagem processual da interação professor/aluno. Campinas, SP: Mercado de Letras, 2001.

NURC. Normas para transcrição. In: PRETI, D. (org.) Estudos de língua falada: variações e confrontos. São Paulo: Humanitas/ FFLCH/ USP, 1998, p.12-13.

PEREIRA, B. A. o gênero debate no ensino de português: do livro didático à sala de aula.173f. Dissertação (Mestrado em Linguagem e 
Ensino). Centro de Humanidades, Universidade Federal de Campina Grande, Campina Grande-PB, 2011.

RAFAEL, E. L. Construção dos conceitos de texto e de coesão textual: da linguística à sala de aula. $228 \mathrm{f}$. Tese (Doutorado em Linguística Aplicada). Instituto de Estudos da Linguagem, Universidade Estadual de Campinas, São Paulo, 2001a.

O gênero debate no ensino de português

ROJO, R. Livros em sala de aula: modos de usar. In: CARVALHO, M. A. F.; MENDONÇA, R. H. (org.). Práticas de leitura e escrita. Brasília: MEC, 2006, p. 96-101.

SCHNEUWLY, Bernard; DOLZ, Joaquim. Des objets enseignés en classe de français. Rennes Cedex: Presses Universitaires de Rennes, 2009.

SOUZA, J. C. A. Gêneros e formatos na televisão brasileira. São Paulo: Summus, 2004. 
